\title{
Laparoscopic Supracervical Hysterectomy and Laparoscopic Total Hysterectomy in Patients with Very Large Uteri: a Retrospective Single-Center Experience at a Major University Hospital
}

\author{
Laparoskopische suprazervikale Hysterektomie und totale \\ laparoskopische Hysterektomie bei Patientinnen mit sehr großer \\ Gebärmutter: eine retrospektive monozentrische Untersuchung \\ in einem großen Universitätskrankenhaus
}

Authors

Dorit Schöller ${ }^{1}$, Florin-Andrei Taran ${ }^{1}$, Markus Wallwiener ${ }^{2}$, Birgitt Schönfisch ${ }^{1}$, Bernhard Krämer ${ }^{1}$, Harald Abele ${ }^{1}$, Felix Neis ${ }^{1}$, Christian W. Wallwiener ${ }^{1}$, Sara Brucker ${ }^{1}$

\section{Affiliations}

1 Obstetrics and Gynecology, University of Tübingen, Tübingen, Germany

2 Department of Obstetrics and Gynecology, University of Heidelberg, Heidelberg, Germany

Key words

very large uteri, laparoscopic hysterectomy, conversion to laparotomy, LSH, TLH

\section{Schlüsselwörter \\ received $\quad 18.8 .2016$ \\ revised $\quad 30.1 .2017$ \\ accepted $\quad 31.1 .2017$}

sehr große Gebärmutter, laparoskopische Hysterektomie, Konversion zur Laparotomie, LSH, TLH

Bibliography

DOI http://dx.doi.org/10.1055/s-0043-102695

Geburtsh Frauenheilk 2017; 77: 251-256 @ Georg Thieme Verlag KG

Stuttgart · New York | ISSN 0016-5751

Correspondence

Dr. Dorit Schöller

University of Tübingen, Obstetrics and Gynecology

Calwer Straße 7, 72076 Tübingen, Germany

dorit.schoeller@med.uni-tuebingen.de

\section{ABSTRACT}

Objective The main objectives of our study were to demonstrate that laparoscopic supracervical hysterectomy (LSH) or total laparoscopic hysterectomy (TLH) can be performed safely even in patients with a uterine weight $\geq 500 \mathrm{~g}$, to analyze the rate of conversions to laparotomy due to uterine size and to estimate the incidence and type of intraoperative and long-term postoperative complications.

Study Design Retrospective open, single-center, comparative interventional study of LSH and TLH.

Results The present study comprised a total of 138 patients that underwent laparoscopic hysterectomy with a uterine weight $\geq 500 \mathrm{~g}$;
109 patients $(79.0 \%)$ underwent LSH and 29 patients $(21.0 \%)$ underwent TLH. Median uterine weight across the entire cohort was $602 \mathrm{~g}$, with the largest uterus weighing $1860 \mathrm{~g}$. A total of 24 cases (17.4\%) among the 138 hysterectomies were converted to a laparotomy due to lack of adequate intraabdominal space and size of the uterus. Mean uterine weight of the patients in the LSH group that underwent conversion was $883 \mathrm{~g}($ SD $380 \mathrm{~g}, \mathrm{n}=13$ ) and $757 \mathrm{~g}($ (SD $371 \mathrm{~g}, \mathrm{n}=11)$ in the TLH group. The rate of conversion to laparotomy due to the uterine weight was significantly lower in the LSH group (11.9\%) compared to the TLH group $(37.9 \%)(p=0.002)$. Intraoperative complications requiring laparotomy for other reasons but uterine size occurred in $6 \mathrm{pa}-$ tients of the study cohort $(6 / 138 ; 4.3 \%)$. Long-term postoperative complications occurred in 2 patients $(2 / 138,1.4 \%)$, both patients from LSH group had to be re-operated on due to adhesions.

Conclusions Our study adds further insight in the limited data set of laparoscopic hysterectomy for increased uterine weight and shows that $\mathrm{LSH}$ and TLH are safe and feasible even in patients with very large uteri $(\geq 500 \mathrm{~g})$.

\section{ZUSAMMENFASSUNG}

Ziel Aufgabe dieser Studie war es, nachzuweisen, dass die laparoskopische suprazervikale Hysterektomie (LSH) bzw. die totale laparoskopische Hysterektomie (TLH) auch in Patientinnen mit einem Gebärmuttergewicht von $\geq 500 \mathrm{~g}$ gefahrlos durchgeführt werden kann. Die Anzahl der wegen der Gebärmuttergröße vorgenommenen Umwandlungen von einer laparoskopischen Hysterektomie in eine totale abdominelle Hysterektomie wurde analysiert, sowie die Häufigkeit von intraoperativen und postoperativen Langzeitkomplikationen.

Studiendesign Es handelte sich um eine retrospektive, offene, monozentrische, vergleichende Interventionsstudie von LSH und TLH.

Ergebnisse Insgesamt wurden 138 Patientinnen mit einem Gebärmuttergewicht von $\geq 500 \mathrm{~g}$ in diese Studie aufgenommen. Bei allen Frauen war eine laparoskopische Hysterektomie geplant. Davon haben sich 109 Patientinnen (79,0\%) einer LSH unterzogen, und 29 Patientinnen $(21,0 \%)$ erhielten eine TLH. Das durchschnittliche Gebärmuttergewicht für das gesamte Patientinnenkollektiv betrug $602 \mathrm{~g}$; die schwerste Gebärmutter wog $1860 \mathrm{~g}$. Bei insgesamt 24 Frauen (17,4\%) aus dem Gesamtkollektiv von 138 Patientinnen musste, wegen der Größe der Gebärmutter und weil es intraabdominal an ausreichendem Platz mangelte, die laparoskopische Hysterektomie in eine Laparotomie umgewandelt werden. Das durchschnittliche uterine Gewicht bei den Patientinnen in der LSH-Gruppe, bei denen eine Konversion erfolgte, betrug $883 \mathrm{~g}$ (SD $380 \mathrm{~g}, \mathrm{n}=13$ ) bzw. $757 \mathrm{~g}(\mathrm{SD} 371 \mathrm{~g}, \mathrm{n}=11)$ 
bei den Patientinnen der TLH-Gruppe. Die Konversionsrate zur Laparotomie infolge des Gebärmuttergewichts war wesentlich geringer in der LSH-Gruppe (11,9\%) verglichen mit der TLH-Gruppe (37,9\%) $(p=0,002)$. Bei 6 Patientinnen $(6 / 138 ; 4,3 \%)$ traten intraoperativ Komplikationen aus anderen Gründen als der Gebärmuttergröße auf, die eine Umwandlung in eine Laparotomie erforderlich machten. Postoperative Langzeitkomplikationen traten bei 2 Patientinnen auf (2/138, 1,4\%); beide Patientinnen aus der LSH-Gruppe mussten sich einer Zweitoperation wegen Adhäsionen unterziehen.
Schlussfolgerungen Unsere Studie liefert weitere Erkenntnisse zu den begrenzten Daten über den Einsatz der laparoskopischen Hysterektomie bei schweren und großen Gebärmüttern und zeigt, dass LSH und TLH sicher und durchführbar sind, selbst bei Patientinnen mit sehr großen Gebärmüttern ( $\geq 500 \mathrm{~g}$ ).

\section{Introduction}

Uterine leiomyomas (fibroids, myomas) are benign myometrial neoplasms, but may grow to impressive sizes [1]. Furthermore, leiomyomas represent the primary indication for hysterectomy, one of the most common surgically performed procedures in women, in Germany and the United States [2]. Traditionally, hysterectomy for very large uteri has been performed abdominally. However, since the introduction and considerable improvement of the laparoscopic technique, e.g. improvements in uterine morcellation and thermal coagulation, the use of laparoscopic hysterectomy for benign gynecologic disease has increased substantially, but this surgical procedure is still underused [3-4].

The benefits of a laparoscopic approach to hysterectomy are well documented in literature. The concerns and difficulties with the minimally invasive approach for enlarged uteri are limited access to uterine vessels with a high risk of hemorrhage or injury of bowel or bladder due to poor exposure, difficulty extracting the uterus and the duration of the procedure [6]. As a consequence, for very large uteri weighing at least 500 grams (g) the most suitable type of approach is still subject of debate [5]. To date, only one prospective randomized study and few retrospective studies assessed the feasibility of laparoscopic hysterectomy in cases of very large uteri. Most studies demonstrated the feasibility and safety of laparoscopic hysterectomy compared to normal uterine size with a longer operation time and a low level of operative complications [4-10]. However, the existing studies analyzed different hysterectomy techniques: total laparoscopic hysterectomy (TLH), laparoscopically assisted vaginal hysterectomy (LAVH) and laparoscopic supracervical hysterectomy (LSH). Most studies focused on TLH and did not compare the techniques among each other for large uteri [4-10]. Moreover, another limitation of the existing studies is the definition of the enlarged uterus with a range from $300 \mathrm{~g}$ up to $1000 \mathrm{~g}$ [4-10]. The general consensus defines a large uterus as a uterus extending beyond the boundaries of the true pelvis, which equates to a 20 -week sized uterus or to a uterine weight of $500 \mathrm{~g}$.

The main objectives of our study were to demonstrate that LSH or TLH can be performed safely even in patients with a uterine weight $\geq 500 \mathrm{~g}$, to analyze the rate of conversions to laparotomy due to uterine size and to estimate the incidence and type of intraoperative and long-term postoperative complications. Our secondary objective was to compare LSH and TLH with regard to conversion to laparotomy rate. The women included in the present study derive from the same cohort as our prospective implementation and standardization study on LSH and TLH for benign uterine disease [11].

\section{Material and Methods}

\section{Study design}

All women included in the study underwent either LSH or TLH for benign uterine disease at the Department of Obstetrics and Gynecology, University Tübingen, Germany from January 2003 to December 2010. Inclusion criteria for this retrospective open, single-center, comparative interventional study of LSH and TLH have been previously described in detail [11]. Briefly, women aged over 18 years, with symptomatic, benign uterine disease were either planned for either LSH or TLH in accordance with our institution's guidelines [11-12]. Additionally, for the present analysis we included only women with a uterine weight of at least 500 grams (g). Exclusion criteria included presence of gynecologic cancers, planned laparotomy, deep infiltrating endometriosis and urogenital prolapse. The women included in the present study derive from the same cohort as our prospective implementation and standardization study on LSH and TLH for benign uterine disease, which analyzed the standard hysterectomy and therefore excluded complex situations [11].

Demographic variables (including age, body mass index [BMI], and a previously described surgery score, calculated as 1 point per laparoscopy plus 2 points per laparotomy (including cesarean sections) [13], surgical (e.g. operating time) and pathological (uterine weight, histological diagnosis) variables were collected and extracted from hospital records for statistical analysis. Operating time was measured from insertion of the Verres needle to skin closure; the length of hospital stay was calculated in days [11].

\section{Surgical strategies}

The surgical techniques for LSH and TLH were essentially performed as previously described, in the context of implementation of standardized surgical methods and including the introduction of innovative instruments [12]. However, if required certain modifications to the standard technique were adopted: myomectomy may have been done prior to the hysterectomy in case of large subserosal leiomyomas in order to create space for the procedure. We defined conversion to laparotomy as the need for a standard laparotomy at any time during the operation, either because of complications or technical difficulties [11]. All patients under- 


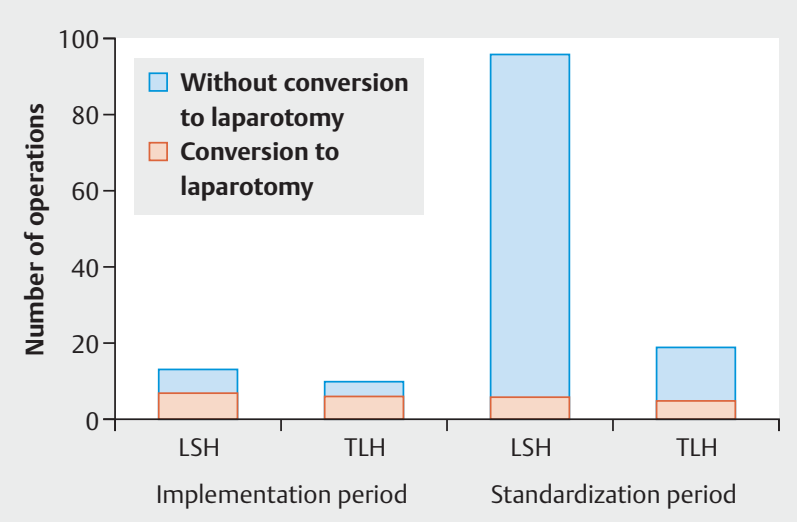

- Fig. 1 Number of supracervical and total laparoscopic hysterectomies with number of conversion to laparotomy due to large uteri (red) during the implementation period (LSH 2003-2006; TLH 2003-2008) and standardization period (LSH 2007-2010; TLH 2009-2010). going TLH were strongly advised to abstain from sexual intercourse from at least 6 weeks after surgery. The hysterectomies were performed by 12 gynecologic surgeons from our Department; the size of the study cohort reflects the entire laparoscopic experience of these surgeons starting with the first laparoscopic hysterectomy in a woman meeting the inclusion criteria within the implementation and standardization period of the techniques ( $\bullet$ Fig. 1).

\section{Data analysis}

Data were coded and entered into an Excel spread sheet (Microsoft, Redmond, Washington). Statistical analysis was carried out using R (Version 3.1.2., with package exact RankTests) (R: A Language and Environment for Statistical Computing, R Development Core Team, R Foundation for Statistical Computing, Vienna, Austria, 2014, www.r-project.org). We report means, standard deviations and medians for continuous variables and frequency counts and percentages for nominal or categorical variables. To assess differences between the LSH and the TLH group, Fisher's exact tests were performed for nominal or categorical variables. The Wilcoxon sum rank test was performed for continuous variables. All tests were two tailed and $p<0.05$ was considered statistically significant in all statistical analyses.

\section{Results}

A total of 2291 consecutive patients underwent hysterectomy at our institution during the study period and were assessed for inclusion in the present analysis. Of these patients, 2153 patients were excluded: 283 patients had gynecologic malignancy, 27 patients underwent planned laparotomy due to individual risk-benefit analysis, 29 patients were excluded for other reasons (including 15 patients who had borderline malignancies). Of the remaining 1814 patients 138 had a uterine weight of at least $500 \mathrm{~g} ; 109$ pa-

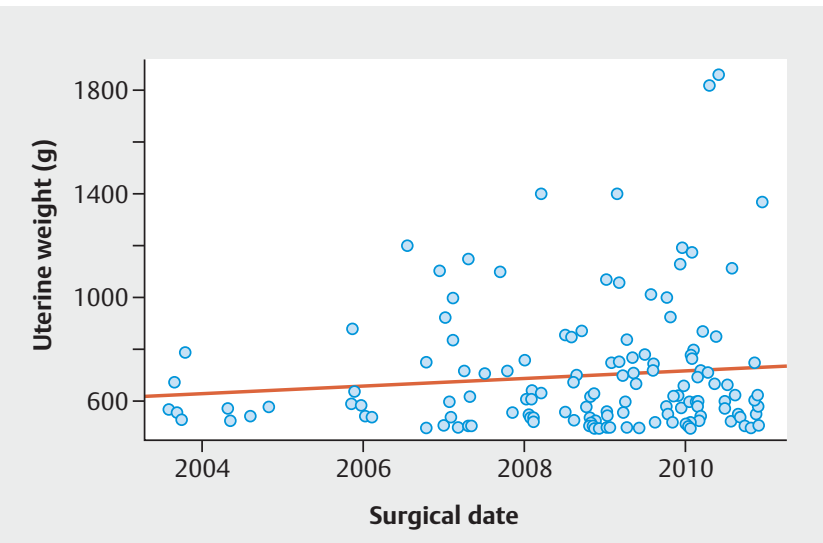

- Fig. 2 Distribution of laparoscopic supracervical and total hysterectomies according to uterine weight and surgical date.

tients (79.0\%) underwent LSH and 29 patients (21.0\%) underwent TLH.

\section{Patient population}

The main indication of hysterectomy in our study cohort was the preoperative diagnosis of leiomyomas (92.0\%). Patient ages ranged from 36 to 67 years, with an overall median of 47.5 years; median BMI was 24.9 for all patients, ranging from 18.3 to 45.9. Prior pelvic or abdominal surgery was noted in almost half of the women (45.7\%). Median uterine weight across the entire cohort was $602 \mathrm{~g}$, with the largest uterus weighing $1860 \mathrm{~g}$.

The 138 hysterectomies were carried out by 12 surgeons; one surgeon performed $>20$ cases, 3 performed $>15$ cases and 3 performed $>10$ cases, altogether accounting for 111 (80.4\%) of all hysterectomies. The remaining 5 surgeons performed up to 8 hysterectomies. - Fig. 2 shows the uterine weight by surgery date; the slight increase of uterine weight by time is not significant (linear regression, $p=0.225$ ) ( $\bullet$ Fig. 2 ).

Selected baseline demographic characteristics of the two distinct groups are shown in - Table 1. No significant differences in characteristics were found among women that underwent LSH compared to women that underwent TLH with regard to age, $\mathrm{BMI}$, and previous surgery score ( $\bullet$ Table 1 ). The intra- and postoperative characteristics of the study cohort are presented in detail in $>$ Table 2 . The two groups of women did not differ significantly in respect of uterine weight, operative time and hemoglobin drop. The hospital stay was significantly shorter in women that underwent LSH compared to women that underwent TLH $(p<0.001)$.

\section{Conversion to laparotomy}

The rate of conversion to laparotomy was significantly lower in the LSH group (16.5\%) compared to the TLH group (41.4\%) $(p=0.009)$ ( $\triangleright$ Table 2$)$. A total of 24 cases $(17.4 \%)$ among the 138 hysterectomies were converted to a laparotomy due to lack 
- Table 1 Baseline demographic characteristics of patients with large uteri.

\begin{tabular}{|c|c|c|c|}
\hline Characteristic & LSH $(n=109)$ & TLH $(n=29)$ & p-value (Wilcoxon test) \\
\hline Age (years), mean (SD) & $47.7(5.3)$ & $46.6(4.7)$ & $p=0.580$ \\
\hline $\operatorname{BMI}\left(\mathrm{kg} / \mathrm{m}^{2}\right)$, mean $(\mathrm{SD})$ & $26.2(5.8)$ & $26.1(4.3)$ & $p=0.544$ \\
\hline Previous surgery score*, mean (SD) & $1.2(1.5)$ & $0.7(1.0)$ & $p=0.112$ \\
\hline
\end{tabular}

- Table 2 Intra- and postoperative characteristics of patients with large uteri.

\begin{tabular}{|l|c|c|c|}
\hline Characteristic & LSH $(\mathbf{n = 1 0 9 )}$ & TLH (n=29) & $\begin{array}{l}\text { p value (Wilcoxon test } \\
\text { resp. Fisher exact test) }\end{array}$ \\
\hline Uterine weight (g), mean (SD) & $702(248)$ & $695(253)$ & $\mathrm{p}=0.500$ \\
\hline Operative time (min), mean (SD) & $130(46)$ & $142(36)$ & $\mathrm{p}=0.073$ \\
\hline Conversion to laparotomy, $\mathrm{n}(\%)$ & $18(16.5)$ & $12(41.4)$ & $\mathrm{p}=0.009$ \\
\hline Hemoglobin drop (g/dL), mean (SD) & $1.4(1.0)$ & $1.9(1.2)$ & $\mathrm{p}=0.156$ \\
\hline Hospital stay (days), mean (SD) & $4.6(1.5)$ & $7.0(5.3)$ & $\mathrm{p}<0.001$ \\
\hline
\end{tabular}

of adequate intraabdominal space and size of the uterus, 5 (20.8\%) of these patients (4 in LSH group, 1 in TLH group) had uterine weights $>1000 \mathrm{~g}$. Mean uterine weight of the patients in the LSH group that underwent conversion was $883 \mathrm{~g}$ (SD $380 \mathrm{~g}$, $\mathrm{n}=13)$ and $757 \mathrm{~g}($ SD $371 \mathrm{~g}, \mathrm{n}=11)$ in the TLH group. The rate of conversion to laparotomy due to the uterine weight was significantly lower in the LSH group (11.9\%) compared to the TLH group $(37.9 \%)(p=0.002)$. Intraoperative complications requiring laparotomy for other reasons but uterine size occurred in 6 patients of the study cohort $(6 / 138 ; 4.3 \%)$ : 5 patients that underwent LSH (3 patients with complex adhesions, 1 patient with uterine bleeding requiring blood transfusion and 1 patient with severe hypercapnia) and 1 patient that underwent TLH (accidental injury of the inferior vena cava).

Most conversions only due to uterine size occurred during the implementation period of both surgical methods at our institution: 2003 through 2006 for LSH (7 conversions/13 surgical procedures [53.8\%]) versus 2007 to 2010 (6 conversions/96 surgical procedures [6.3\%]) $(p<0.001)$ and 2003 until 2008 for TLH (6 conversions/10 surgical procedures [60.0\%]) vs. 2009 to 2010 (5 conversions/19 surgical procedures [26.3\%]) $(p=0.114)$ Before 2007 TLH was performed only in individual cases ( $\bullet$ Fig. 1).

Severe intra-abdominal adhesions necessitating extensive adhesiolysis were the reason to conversion in one patient and together with large uterus in another patient, both of the LSH group. Intraoperative complications requiring laparotomy occurred in 3 patients of the study cohort, all together with large uteri $(3 / 138 ; 2.2 \%)$ : 2 patients that underwent LSH (one patient with uterine bleeding requiring blood transfusion, one patient with bladder injury) and one patient that underwent TLH (accidental injury of the inferior vena cava). Long-term postoperative complications requiring re-operations occurred in 2 patients (2/
$138,1.4 \%)$ from the LSH group, both patients had to be re-operated on due to adhesions.

\section{Discussion}

Our results show that LSH or TLH in women with very large uteri can be accomplished with few conversions to abdominal hysterectomy due to uterine size, minimal blood loss and a low rate of intraoperative and long-term postoperative complications. In addition, we found that the rate of conversion to laparotomy due to uterine size was significantly lower in the LSH group compared to the TLH group and that the hospital stay was significantly shorter for women that underwent LSH compared to women that underwent TLH.

Generally the rate of conversion to laparotomy in laparoscopic hysterectomy has been reported to range from 0 to $19 \%$ with independent risk factors [14]. We found a conversion rate to laparotomy due to uterine size of $17.4 \%$ in accordance with previously published evidence [14]. However, Alperin et al. found a conversion rate of $3.4 \%$ in the largest series of $\mathrm{LSH}$ and TLH for very large uteri ( $\geq 500 \mathrm{~g}$ ) reported to date [4]. Furthermore, Uccella et al. reported a conversion rate of $4.2 \%$ in a series of women that underwent TLH for uteri weighing $\geq 1000 \mathrm{~g}$ [9]. A possible explanation for difference reflected by our cohort is the fact that the size of our study cohort reflects the entire laparoscopic experience of the surgeons starting with the first laparoscopic hysterectomy in a woman meeting the inclusion criteria while the laparoscopic experience was not specified in the previously mentioned studies. Accordingly, the conversion rate due to uterine size only decreased markedly after the successful implementation of LSH and TLH in our Department (13 conversions/23 surgical pro- 
cedures [56.5\%] vs. 11 conversions/115 surgical procedures [9.56\%]). Wallenstein et al. reported a $25 \%$ risk reduction in laparoscopic hysterectomies if the operation was performed by a high-volume surgeon and $18 \%$ if the patient was treated at a high-volume center. The overall complication rate decreased from $6.2 \%$ for low-volume surgeons to $4.2 \%$ for high-volume surgeons [15]. An increased uterine size not only requires greater surgical skills and experience, but also adequate technical equipment and in some cases a modification of the technique [16-17].

Wattiez et al. described several modifications to the current technique for TLH for huge uteri to minimize the risk of lacerating the uterus such as a higher insertion of the optic trocar via an open abdominal entry [6]. Also the use of a uterine manipulator appears very helpful in these cases to reduce the risk of complications and the operating time as it optimizes the exposure of vessels and structures [18].

For laparoscopically assisted hysterectomy for uteri weighing $500 \mathrm{~g}$ or more was described that conversion to total abdominal hysterectomy could be expected to occur in less than $10 \%$ of cases [7]. The risk of conversion is increased at BMI $>35$, age $>65$ years and uterus weight 200 to $500 \mathrm{~g}$ and especially $>500 \mathrm{~g}$ as well as surgical skills [14]. Wallwiener et al. showed that a surgical history of two or more cesarean sections is a risk factor for operative complication and that a $\mathrm{BMI} \geq 30 \mathrm{~kg} / \mathrm{m}^{2}$, uterine weight $\geq 500 \mathrm{~g}$ and a surgical history of myomectomy are risk factors for conversion to laparotomy [11]. On the contrary, Alperin et al. found no association between conversion rate and increased uterine weight [4].

Of note, the conversion rate was significantly lower in the LSH group compared to the TLH group. Twijnstra et al. also observed an approximate three-fold decrement of the conversion risk to laparotomy when performing LSH compared to TLH [14]. Additionally, no direct association of the surgical experience with the conversion rate was found [14]. However, Twijnstra et al. introduced the term of "surgical skills" (a summation of immeasurable "environmental" factors: factors related to the surgeon, the operating room team, or organizational factors), an intrinsic factor influencing the risk of conversion [14]. In our opinion, our finding of a lower conversion rate in the LSH group can also be explained in the light of "surgical skills": at the beginning of the implementation period (year 2003) LSH and TLH were performed in a ratio of $21: 1$, while at the end of the implementation period (year 2008) LSH and TLH were performed in a ratio of 5:1 ( Fig. 2 ). Thus, the increment of surgical procedures does not only influence the surgical experience, but also the "surgical skills" of the entire surgical team.

The rate of intraoperative complications (2.2\%) (blood transfusion, cystotomy, injury of the inferior vena cava) and long-term postoperative complications (1.4\%) (re-operations due to adhesions) is in accordance with previously published rates in patients with increased uterine weight [4]. Hence, supposed that experienced surgical skills and adequate technical equipment are assured, laparoscopic hysterectomy can be performed successfully in most women with enlarged uteri with no significant increase in complication rates, so that these patients can benefit by the advantages related to minimally invasive surgery.
The major limitation of the present study is the non-randomized approach to the surgical indication of either LSH or TLH which leads to the possibility of selection bias. Furthermore, similarly to the series of Alperin et al., the study did not include open abdominal or vaginal hysterectomy comparison groups [4]. However, by choosing to analyze data from consecutive cases, representing the entire laparoscopic experience of LSH and TLH in patients with very large uteri, starting with the first laparoscopic hysterectomy in a woman meeting the inclusion criteria, we have presented unbiased outcomes. In conclusion, our study adds further insight in the limited data set of laparoscopic hysterectomy for increased uterine weight and shows that after an implementation period LSH and TLH are safe and feasible even in patients with very large uteri $(\geq 500 \mathrm{~g})$.

\section{Conclusions}

Our study adds further insight in the limited data set of laparoscopic hysterectomy for increased uterine weight and shows that LSH and TLH are safe and feasible even in patients with very large uteri $(\geq 500 \mathrm{~g})$.

\section{Conflict of Interest}

None.

\section{References}

[1] Stewart EA. Uterine fibroids. Lancet 2001; 357: 293-298

[2] Fernandez H, Farrugia M, Jones SE et al. Rate, type, and cost of invasive interventions for uterine myomas in Germany, France, and England. J Minim Invasive Gynecol 2009; 16: 40-46

[3] Brucker S, Solomayer E, Zubke W et al. A newly developed morcellator creates a new dimension in minimally invasive surgery. J Minim Invasive Gynecol 2007; 14: 233-239

[4] Alperin M, Kivnick S, Poon KY. Outpatient laparoscopic hysterectomy for large uteri. J Minim Invasive Gynecol 2012; 19: 689-694

[5] Fiaccavento A, Landi S, Barbieri F et al. Total laparoscopic hysterectomy in cases of very large uteri: a retrospective comparative study. J Minim Invasive Gynecol 2007; 14: 559-563

[6] Wattiez A, Soriano D, Fiaccavento A et al. Total laparoscopic hysterectomy for very enlarged uteri. J Am Assoc Gynecol Laparosc 2002; 9: 125-130

[7] Pelosi MA, Kadar N. Laparoscopically assisted hysterectomy for uteri weighing $500 \mathrm{~g}$ or more. J Am Assoc Laparosc 1994; 1: 405-409

[8] Salmanli N, Maher P. Laparoscopically-assisted vaginal hysterectomy for fibroid uteri weighing at least 500 grammes. Aust N Z J Obstet Gynaecol 1999; 39: 182-184

[9] Uccella S, Cromi A, Serati M et al. Laparoscopic hysterectomy in case of uteri weighing $\geq 1$ kilogram: a series of 71 cases and review of the literature. J Minim Invasive Gynecol 2014; 21: 460-465

[10] Lyons TL, Adolph AJ, Winer WK. Laparoscopic supracervical hysterectomy for the large uterus. J Am Assoc Gynecol Laparosc 2004; 11: 170174 
[11] Wallwiener M, Taran FA, Rothmund R et al. Laparoscopic supracervical hysterectomy (LSH) versus total laparoscopic hysterectomy (TLH): an implementation study in 1,952 patients with an analysis of risk factors for conversion to laparotomy and complications, and of procedure-specific re-operations. Arch Gynecol Obstet 2013; 288: 1329-1339

[12] Wallwiener D, Becker S. Atlas of gynecologic Surgery. 4th ed. Stuttgart: Thieme; 2013

[13] Boosz A, Lermann J, Mehlhorn G et al. Comparison of re-operation rates and complication rates after total laparoscopic hysterectomy (TLH) and laparoscopy-assisted supracervical hysterectomy (LASH). Eur J Obstet Gynecol Reprod Biol 2011; 158: 269-273

[14] Twijnstra AR, Blikkendaal MD, van Zwet EW et al. Clinical relevance of conversion rate and its evaluation in laparoscopic hysterectomy. J Minim Invasive Gynecol 2013; 20: 64-72
[15] Wallenstein MR, Ananth CV, Kim JH et al. Effect of surgical volume on outcomes for laparoscopic hysterectomy for benign indications. Obstet Gynecol 2012; 119: 709-716

[16] Malzoni M, Perniola G, Perniola F et al. Optimizing the total laparoscopic hysterectomy procedure for benign uterine pathology. J Am Assoc Gynecol Laparosc 2004; 11: 211-218

[17] Wattiez A, Soriano D, Cohen SB et al. The learning curve of total laparoscopic hysterectomy: comparative analysis of 1647 cases. J Am Assoc Gynecol Laparosc 2002; 9: 339-345

[18] Mueller A, Boosz A, Koch M et al. The Hohl instrument for optimizing total laparoscopic hysterectomy: results of more than 500 procedures in a university training center. Arch Gynecol Obstet 2011; 285: 123-127 